\title{
Research of features related to land subsidence and ground fissure disasters in the Beijing Plain
}

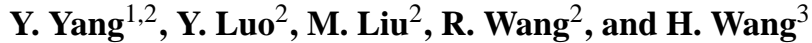 \\ ${ }^{1}$ School of Earth and Space Sciences, Peking University, Beijing, China \\ ${ }^{2}$ Beijing Institute of Hydrogeology and Engineering Geology, Beijing, China \\ ${ }^{3}$ China Institute of Geo-Environment Monitoring, Beijing, China
}

Correspondence to: Y. Yang (yangyanhunan1982@126.com)

Published: 12 November 2015

\begin{abstract}
This study overviews the development history, current situation, impact, and hazards of land subsidence and ground fissure disasters in the Beijing Plain (BP) and focuses on the disaster distribution and features of disaster-causing mechanisms. Currently, the BP is still in a rapid developmental stage of land subsidence. The development and distribution of land subsidence are affected by various factors including the thickness of Quaternary compressible clay, groundwater overexploitation, and the rapid development of urban construction. The causes of ground fissures in the BP are complex and diverse, with evidence of structure fissures, non-structure fissures, and mixed genesis fissures. Investigations of the Gaoliying ground fissure have shown that this fissure has evidence of fracture activity, with vertical deformation that is more significant than horizontal deformation. Furthermore, this ground fissure has characteristics of inter-annual periodicity and annual jumping. The land subsidence and ground fissures are all under structural control and impact each other, and more severe hazards may be induced under the superimposition of these two types of disasters. Effective measures and suggestions for disaster prevention and control are recommended on the basis of this study.
\end{abstract}

\section{Introduction}

Land subsidence is one of the most pervasive developmental geological disasters in the Beijing Plain (BP). The subsidence area has accounted for approximately $2 / 3$ of the entire BP up to 2014, with a maximum accumulative subsidence of over $1.6 \mathrm{~m}$ and a maximum subsidence rate of more than $150 \mathrm{~mm}$ year $^{-1}$ (Yang et al., 2010). The BP is still in the rapid developmental stage of land subsidence. The land subsidence monitoring in the BP started in the 1980s, and has been greatly improved over the past decade. Several monitoring methods have been utilized including InSAR, GPS, extensometers, and high-precision level measurements. Furthermore, the monitoring network has covered almost the entire plain.

The distribution and development of ground fissures in the BP are apparently affected by geological structures, and most of them are caused by multiple geneses. In recent years, exploratory trench excavations, automatic monitoring, and level measurements of ground deformation have been conducted to obtain more detailed information of these fissures. Furthermore, a special monitoring station has been constructed in the Shunyi district.

The land subsidence and ground fissures can potentially damage buildings and other constructions, reduce the value of land use, threaten the safety of track traffic, decrease the ground levels as well as reduce the capability of urban flood control and drainage, resulting in extensive economic and social losses (Yang et al., 2013).

\section{Characteristics of land subsidence}

\subsection{Distribution}

The land subsidence in the BP mainly develops in the lower and middle parts of the diluvial-alluvial plain. The connecting parts among the diluvial-alluvial fans of the Wenyu River, Chaobai River, and Yongding River have become one of the largest subsidence regions in the $\mathrm{BP}$, resulting in 


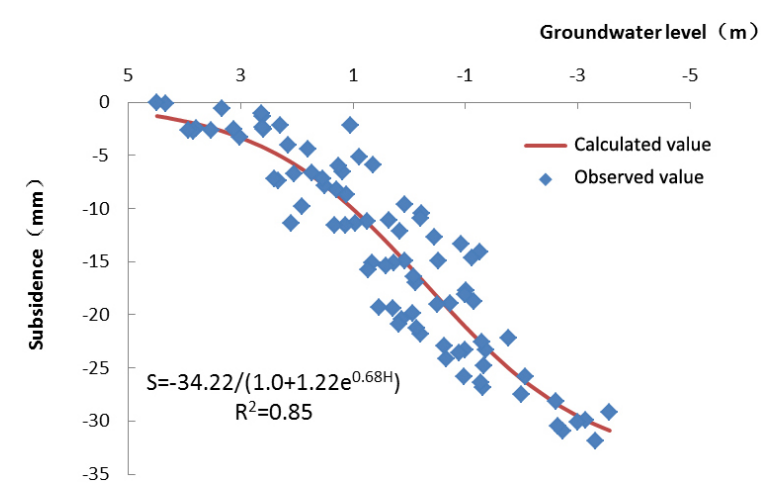

Figure 1. The relationship between groundwater levels and land subsidence in the stratum 66-94 m below the ground surface.

the greatest subsidence area and the maximum subsidence amount and subsidence rate.

The most serious subsidence areas in the BP coincide well with the distribution of the thickness of Quaternary compressible clay. The Quaternary depositional environment in the BP is complex, with sediments displaying alternating sequences of sand and clay layers and complex structures (Jia et al., 2011). The land subsidence develops significantly in areas where the total thickness of compressible layers is greater than $150 \mathrm{~m}$.

\subsection{The development of land subsidence is controlled by variations of groundwater levels}

The overexploitation of groundwater is the most important factor that contributes to the emergence and development of land subsidence in the BP. Monitoring data obtained from measurements of land subsidence and groundwater levels over several years indicate similar decreasing trends (Fig. 1). In regions where a continuous decrease of groundwater levels is observed, the land subsidence develops rapidly and the accumulated subsidence increases continuously. However, in regions where the groundwater levels increase, the subsidence rate becomes slower and the ground may experience minor rebounding in some local areas.

\subsection{Effects of city construction on land subsidence}

With the rapid development of urban construction and continuous growth of the urban population, water demand has increased significantly; consequently, groundwater depression cones and subsidence bowls have occurred. Therefore, urban construction has led to the formation of ground settlement and resulted in the rapid development of land subsidence.

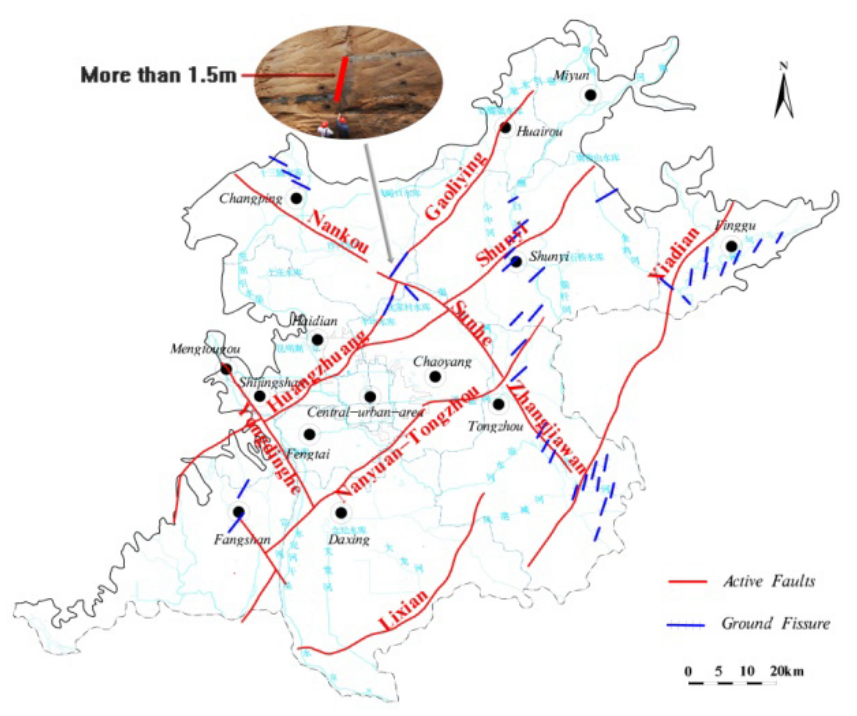

Figure 2. The distribution of ground fissures in the BP.

\section{Characteristics of ground fissures}

\subsection{Distribution}

Beijing is located at the junction between the Yanshan fold and thrust belt (mountain area) and the Huabei fault sag (plain area), and has experienced multi-stage tectonic movements such as the Indosinian, Yanshan, and Himalayan events. Historically, several strong earthquakes have occurred in the area, creating ground fissures in different regions such as Shunyi, Pinggu, Changping, and Tongzhou.

There are two main groups of active faults in the BP: the NE-trending fault belt comprising the HuangzhuangGaoliying fault, Shunyi fault, Xiadian fault, and the NWtrending Nankou-Sunhe fault. The ground fissures mainly occur along active faults (Fig. 2).

\subsection{Causes of ground fissures}

Ground fissures are divided into structure fissures, nonstructure fissures, and mixed genesis fissures according to the origin type. All three types of ground fissures can be found in the BP, and the mixed genesis fissures are the most common type. The mixed-genesis fissures are mainly controlled by endogeneic forces in the Earth and can be intensified by human activities. The Shunyi ground fissure belt, Gaoliying ground fissure, Tugou ground fissure belt, and Yangfang-Miaojuan ground fissure belt belong to the class of mixed genesis fissures. Structure fissures are caused by endogenic geological processes. Their formation, size, and level of destruction have direct relationships with earthquakes, fault activities, and the regional tectonic stress field. For example, after the Tangshan earthquake in 1976, some ground fissures occurred in the BP, which damaged buildings as well as houses and caused panic among the population. Non-structure fissures 


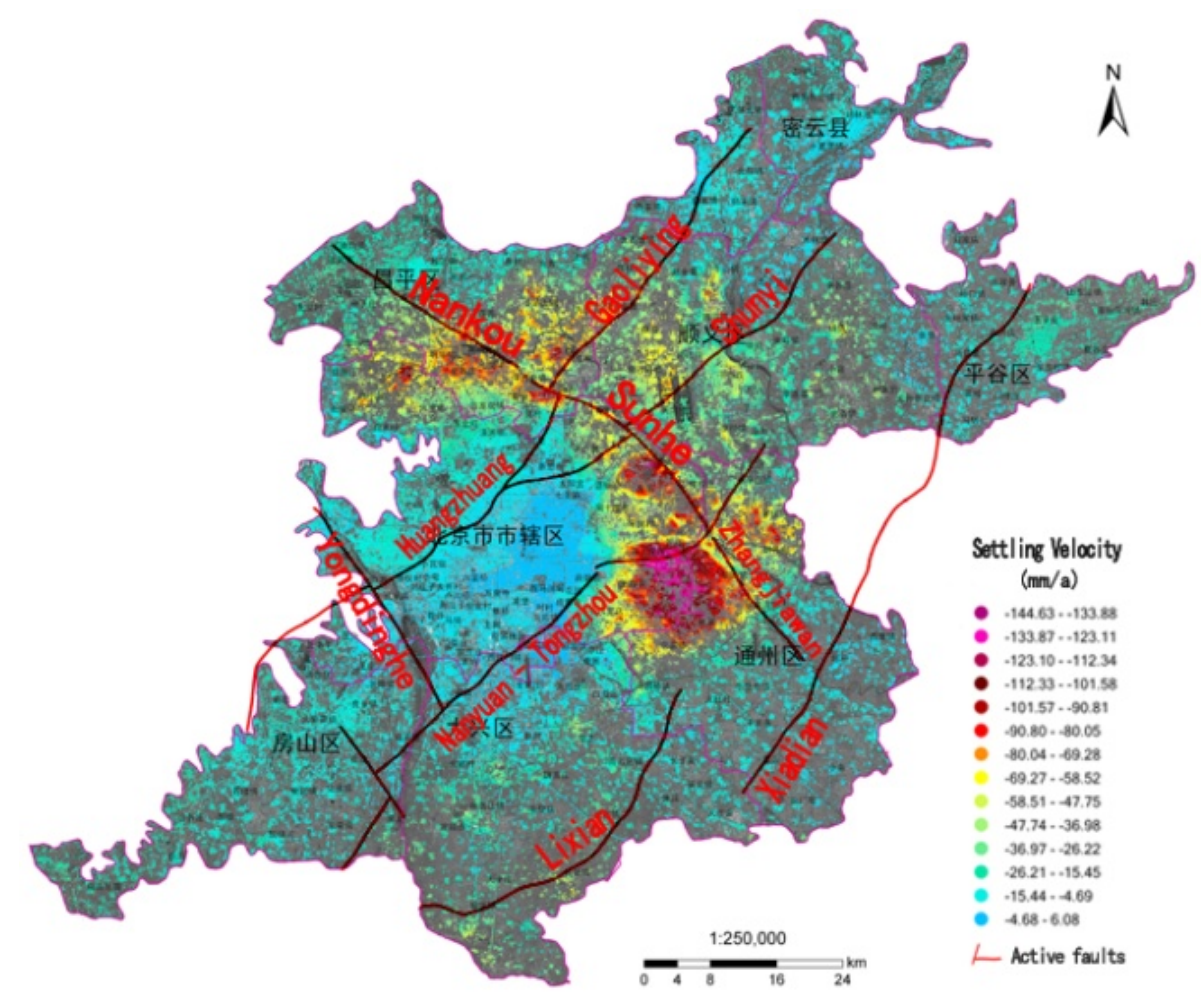

Figure 3. Distribution of subsidence rates and active faults in the BP.

are caused by exogenic geological processes, which have different origins and types. In the BP, the non-structure fissures include collapsing ground fissures, special soil ground fissures, and soil-liquefaction ground fissures.

\subsection{Activity characteristics of ground fissures}

The Gaoliying ground fissure, for example, is under the joint influence of both creeping slip of the HuangzhuangGaoliying fracture and differential settlement of the ground surface. Exploratory trenches show that this fracture has crossed over the entire Quaternary strata. The fracture plane is exposed at the ground surface and has the same location as the ground fissure. The monitoring results of differential settlement on both sides of the fault correspond well with the monitoring results of regional land subsidence.

The surface displacements of the Gaoliying fissure were obtained from the KLA-1 type automatic telemetering system. The results indicate that the ratio of the horizontal torsional displacement, horizontal extension, and vertical differential settlement show obvious three-dimensional activity characteristics (Wang et al., 2013). Some engineering characteristics have also been observed such as similar disaster impacts, limited disaster-causing width, and progressive disaster processes (Liu et al., 2014).

\section{The relationship between land subsidence and ground fissures}

\subsection{All controlled by geological structures}

As shown in Fig. 2, most ground fissures are distributed along active fractures, indicating that they are greatly controlled by geological structures.

The land subsidence in the BP is also controlled by geological structures. Figure 3 shows the distribution of the subsidence rate from InSAR data and the active faults in the BP. The northwestern subsidence area is mostly controlled by the Nankou-Sunhe fracture and Huangzhuang-Gaoliying fracture, where the development trend of the subsidence is essentially parallel to the trend of the fractures. The northeastern subsidence area is mostly controlled by the Shunyi fracture. The eastern East-Balizhuang-Dajiaoting subsidence area is controlled by the Shunyi fracture and the NanyuanTongzhou fracture. The main influence from tectonic movements causes the tectonic units to decline entirely and slowly under the regional stress field. Furthermore, the relative rise and decline of the hanging walls or the footwalls have some impact on the difference in the subsidence rate between the two sides of the fractures.

The distribution of the average subsidence rates in two cross-sections at the Huangzhuang-Gaoliying fracture and Nanyuan-Tongzhou fracture are shown in Fig. 4. The defor- 

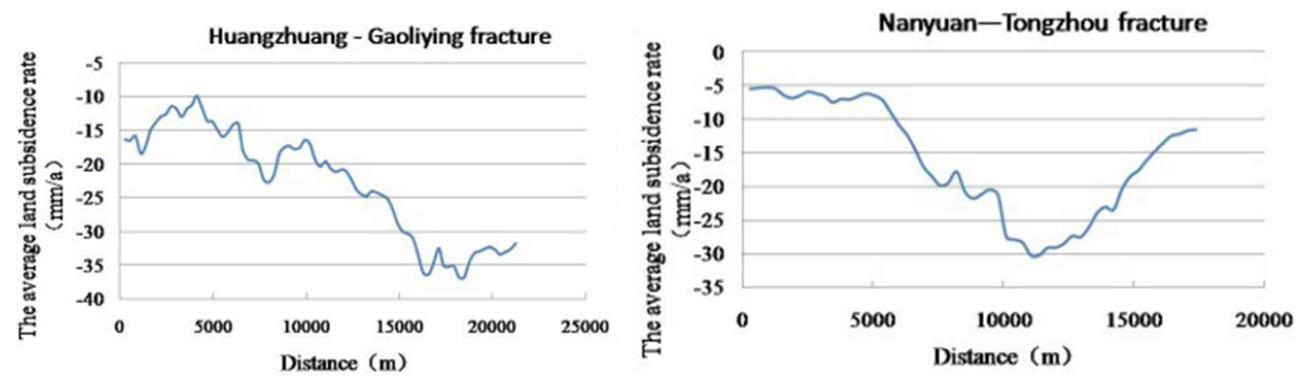

Figure 4. Deformation gradient map in two cross-sections at the Huangzhuang-Gaoliying fracture and Nanyuan-Tongzhou fracture.

mation gradient of the ground surface is relatively large along the two cross-sections, with maximum differences of nearly 28 and $25 \mathrm{~mm}$ year $^{-1}$, respectively.

\subsection{Interplay between land subsidence and ground fissures}

Mixed genesis fissures are the most common type in the BP. In the developmental areas of ground fissures, the lithology is commonly different on both sides of the fissure. When the influence of surface load and soil self-weight impacts and changes, the original groundwater flow field, obvious differential settlement may occur due to the different stratigraphic textures and saturated conditions on either side of the fissure. In contrast, ground fissures may be induced as the differential settlement increases to a certain degree. The damage of ground fissures will increase greatly with the joint function of the differential settlement and active faults, which will intensify the damage to buildings. Therefore, the developmental areas of ground fissures coincide well with the serious areas of land subsidence; i.e., the ground fissures are very active in areas with obvious differential settlement.

\section{Summary and conclusions}

Land subsidence and ground fissures are widely distributed in the BP. They are affected by several factors, likely controlled by geological structures, and have impacts on each other. In the near future, land subsidence and ground fissure disasters will rapidly develop, threatening urban construction and safety.

The common characteristics of land subsidence and ground fissures are slow and irreversible. Thus, prevention is a priority and it should be efficiently combined with control procedures. When new cities and towns are planned and major linear infrastructure and buildings are built, it is necessary to avoid the areas of severe land subsidence and ground fissures as much as possible. The design for these projects must be strict to reduce the influence of these hazards in the new development areas.
Acknowledgements. Thanks to my institute and all colleagues, for their efforts to finish this report results. Thank Ye Shu-jun, Gong Shi-liang and Zhang Jin-jiang, who have been encouraging.

\section{References}

Jia, S., Wang, H., Ye, C., and Liu, M.: Investigation and survey methods appropriate for ground fissure in Beijing, Journal of Engineering Geology, 19, 104-111, 2011.

Liu, M., Jia, S., Chen, Z., and Guo, G.: Study of the activity and impact of the Gaoliying ground fissure on the Beijing plain, Shanghai Land \& Resources, 35, 53-57, 2014.

Wang, H., Yang, Y., Liu, M., Jia, S., and Tian, F.: Analysis of the activity of the Gaoliying ground fissure (Beijing) based on automatic monitoring, Shanghai Land \& Resources, 34, 64-67, 2013.

Yang, Y., Jia, S., and Wang, H.: The status and development of land subsidence in Beijing plain, Shanghai Geology, 4, 23-28, 2010.

Yang, Y., Jia, S., Wang, H., and Zhou, Y.: Analysis on impact of land subsidence on planned new cities in Beijing, City Planning Review, 11, 67-71, 2013. 